\title{
The effect of external factors on industry performance: the case of Lalibela City micro and small enterprises, Ethiopia
}

\author{
Abriham Ebabu Engidawe
}

\author{
Correspondence: Abreshman0921@ \\ gmail.com \\ Management Department, Woldia \\ University, Woldia, Ethiopia
}

\begin{abstract}
The purpose of this study was to examine the effect of external factors on industry performance: in micro and small-scale enterprises. To achieve its objectives, the study employed a descriptive and explanatory research design and used quantitative research approach. The target population of the study was 395 MSEs owners working in manufacturing, trade, and service sectors. It used stratified and simple random sampling techniques and the required data have been collected from a sample size of 199 MSEs through standardized 5-point Likert-scale questionnaire. The study used both primary and secondary sources of data. For data analysis purpose, it employed descriptive and inferential statistical data analysis methods like correlation and multiple linear regression analysis. The finding of the study discovered the agreement of respondents to the positively significant relationship between external factors and industry performance in the study area. Specifically, marketing factors, financial factors, infrastructure, work premises factors, trade fair factors, and politicallegal factors all have a positive effect on enterprises' performance in the study area. In addition, the study result shows that financial factors, marketing factors, infrastructure, work premises factors, and trade fair factors have a positive significant effect on industry performance but political-legal factors do not significantly affect the dependent variable industry performance. From the predicting variables, infrastructure has more effect on industry performance than the rest of variables in the study area. The study recommends that the government/micro and small enterprises development offices should maintain different supportive trainings, decrease infrastructural problems, facilitate credit services, and create attractive environment to entice or create productive MSEs. In addition, the MSEs owners should design adoptive plans and programs with the external as well as internal environment to increase their performance.
\end{abstract}

Keywords: Marketing factors, financial factors, infrastructure factors, work premises factors, trade fair factors, political-legal factors, industry performance 


\section{Introduction}

The contribution of micro and small enterprises has been recognized over the world which is one of the mechanisms and strategies to reduce poverty, and intergenerational wealth creation transfer is a focus on the development of MSEs, which generate income and employment opportunities (Belete, 2015). Micro and small enterprises generally account for bulk of the total enterprise population, irrespective of the level of economic and social development of a country. In many countries of the world, particularly those in Africa and Asia, the micro-enterprise sector constitutes the majority of the working population. Micro and small enterprises play various roles in economic development of a nation that include building up local production structure, creating employment opportunity, and achieving a fair distribution of national resource, income, knowledge, and power, and help to promote rural industrialization and promote export market specifically (Mulugeta, 2008).

In Ethiopia, micro and small enterprises play fundamental position for socio monetary development and serve as engines for employment opportunity and methods of improving wealth creation with the aid of supporting the monetary boom Government of Federal Democratic Republic of Ethiopia (GFDRE, 2011) noted in Lencho (2019). However, there are significant doubts about the high quality of administration in this region with policy-makers suggesting that there are particular weaknesses in innovation, lack of monetary access, lack of adequate market, entrepreneurial failure, lack of practical information, and human aid management. As a result, many corporations do no longer attain their full practicable and fail to grow in Ethiopia.

Performance is the act of performing or of doing something successfully; the use of knowledge as unique from in basic terms possessing it. Business organizations should measure their overall performance with the use of set of financial and non-financial symptoms which provide statistics on degree of accomplishing their objective and result. Organizational overall performance entails the use of sources wisely to keep away from wastage Global Entrepreneurship Monitor (GEM, 2004). Kamunge, Njeru, and Tirimba (2014) used special performance warning signs like extend in sales, enterprise growth, client retention, and rise in stock, waste reduction, and value discount in their study of elements affecting the performance of micro and small enterprise, whereas Mashimba and Kühl (2014) examined enterprise performance in phrases of business enterprise income and employer capital investment in machinery as measure of performance. Additionally, Abera (2012) used profitability as a measure of performance in his evaluation of factors affecting the performance of micro and small companies. Based on the assessment of related literature, the performance of MSEs can be measured in terms of financial and non-financial symptoms, that is, increasing profit, growing sales/product or services, and capital development for this study. Abdissa and Fitwi's (2016) study has investigated the factors that affect the performance of SMEs in Bench Maji, Sheka, and Kefa zone unique to the manufacturing, trade, and service provider sector. And it revealed that the significant effect of political, legal, social, working premises, technology, infrastructure, marketing, finance, management, and entrepreneurial competencies on the overall performance of MSEs. Hence, the main reason to conduct this study is to analyze the effect of external factors on industry performance in micro and small enterprises in the study area. 


\section{Statement of the problem}

To obtain its objective of transition to industry, Ethiopia has prolonged a number of commercial enterprise guide approach or coverage to decorate business overall performance and to create conductive commercial enterprise surroundings for MSE growth and development. This coverage aid consists of access to markets, getting the right of entry to finance, getting entry to industrial extension, and getting admission to education and technological support. One of the major challenges that confronted the increase and development of MSEs in Ethiopia is getting the right of entry to enough and sustainable market (EDRI, 2014).

According to Namusonge (2010), the principal factors that affect the overall performance of micro and small firms and continuously altering the business environment are; market access infrastructure, material supply, education, and technical assistance service and also the study conducted by Abera (2012), elicited eight principal challenges which appear to have an effect on the overall performance of MSEs in sub-cities which include inadequate finance, lack of working premises, marketing problems, insufficient infrastructures, terrible administration practices, and technological, entrepreneurial, and politico-legal issues along with bureaucratic bottlenecks system. The discovery indicated external factors and internal factors affect the overall performance of the micro and small enterprises (MSEs) positively.

The study of Kebede and Simesh (2015) examined an effect of internal and external business environmental factors on the performance MSEs in East Gojjam Zone, Ethiopia. The research finding shows that infrastructure and monetary environment, technological environment, and factors related with entrepreneurial commitment have a clear significant relationship with performances of MSEs. Mainly, researchers found that infrastructure and finance had positive impacts on the overall performance of MSEs, while the rest has negative roles.

Akinruwa, Awolusi, and Ibojo's (2013) study found that political-legal factor has no significant effect on industry performance on his study of Nigeria's' SMEs. Similarly, the study of Mezgebe (2012) showed that politico-legal factor did not significantly affect business performance of MSEs in Addis Ababa city. Fetene (2017) finding shows that the monetary elements have been the most influencing predictor variable for SMEs' overall performance followed through infrastructure and politico-legal factors. Working premises were at the fourth role in phrases of its electricity in influencing commercial enterprise overall performance followed through administration and advertising and marketing factor. This study focuses on six external factors or dimension which affects industry performance that is marketing factors, infrastructure factors, financial factors, working premises, trade fair, and political-legal factors which are potential or crucial for micro and small enterprises in the study area.

As mentioned by different authors and researchers, MSEs are the backbones of the country economy especially in developing countries. But in our country Ethiopia, even the government have given high attention to MSEs and try to increase their performance by giving some supports, they are not effective as expected because of different internal and external factors. From external factors, the major problems are lack of credit access, unfavorable infrastructure, insufficient work premise, marketing factors, trade fair factors, and political-legal factors. Although a number of researches are still being finished on factors affecting the performance of micro and small enterprises, they are 
no longer as fantastic as expected and the problem continues, because there is a trouble in understanding and inspecting the inside and contextual elements that affect the performance of micro and small enterprises. Moreover, preceding studies that had performed so far have the center of attention in developed countries and urban areas on overall performance of micro and small enterprises, whereas restricted research are conducted in rural place and most studies ignored vast variables such as trade fair and marketing. Based on the above studies' findings, there is inconsistency in results, and as per the researchers' knowledge, there are few researches conducted relating to this topic in the country specially in the study area; because of the above problems stated, the researcher would like to fill this gap in this study to check out the external factors that have an effect on the overall performance of micro and small enterprises especially working in manufacturing, service, urban agriculture, and trade sectors. Based on the above research problems, the researcher developed the following research questions:

1. What is the effect of financial factors on industry performance in the study area?

2. How marketing factors affect industry performance in the study area?

3. What is the effect of infrastructural factors on industry performance in the study area?

4. What is the effect of work premise factors on industry performance in the study area?

5. How political-legal factors affect industry performance in the study area?

6. What is the effect of trade fair factors on industry performance in the study area?

\section{Objectives of the study}

\section{General objective}

The general objective of the study was to examine the effect of external factors on industry performance in the study area.

\section{Specific objectives}

1. To analyze the effect of financial factors on industry performance in the study area?

2. To examine how marketing factors affect industry performance in the study area?

3. To measure the effect of infrastructural factors on industry performance in the study area?

4. To evaluate the effect of work premise factors on industry performance in the study area?

5. To examine how political-legal factors affect industry performance in the study area?

6. To investigate the effect of trade fair factors on industry performance in the study area?

\section{Literature review}

External factors and their influence on the performance of MSEs

There are a number of financial challenges that face small enterprises. They encompass the high fee of credit, excessive bank prices, and fees. Lack of access to credit/finance is 
almost universally indicated as a key problem for MSEs. Credit constraints function in variety of methods in Ethiopia where undeveloped capital accumulation and saving (Nabintu, N. Factors affecting the performance of small and micro enterprises, Unpublished). According to Akinruwa et al. (2013), finance and performance in MSEs are significantly related with 0.000 at $5 \%$ significant level. This emphasizes that finance has a significant effect on the business overall performance. Most MSEs failed in most developing international locations because of their incapability to gain get admission to credit score facilities.

On the other hand, meagerness of the physical infrastructure is a precept cause of low ranges of funding and unsatisfactory overall performance of micro and small enterprises (Kebede \& Simesh, 2015). World Bank group enterprise survey (WBG, 2011) has identified poor infrastructure as a necessary issue that constrains commercial enterprise overall performance in Ethiopia. The infrastructure problem comprises of bad nation of roads, inaccessibility to land, workspace, electrical energy, and utility. Lack of allocation of suitable land to MSEs in most city and rural areas is a fundamental obstacle to growth and development in the industry.

Factors such as legal and bureaucratic restrictions, unfavorable tax system, complicated rules and regulations political stability, strategic development objectives, the government accomplished institutional promoting and regulatory policy, the government's aid and the business of an institution's regulating legislation, and other political-legal environment will influence industry performance directly or indirectly (Davidsson, 1989).

Abera's (2012) study revealed that marketing factor is consisted of seven items. From these factors, inadequacy of market, difficulty in searching new market, lack of demand forecasting, lack of market information, and absence of relationship with an organization/association that conduct marketing research are critical factors that affect the performance of MSEs engaged in all sectors. In contrast, UNDP (2004), cited in Mengstie (2016), presented market access as a seven-element factor comprising market research, market information, trade fairs, product exhibitions, advertising, packaging, marketing trips and meetings, and subcontracting and outsourcing. Federal Public Procurement Administration Agency has set a rule that enforces public institutions to source positive component of their annual procurement from MSEs. That is, MSEs are given precedence in authorities' procurement.

The other crucial factor for MSEs' growth is working space. In response, although the government has massively built working spaces for MSEs in major cities and towns, working space remains a critical challenge. Amwele (2013) entitled empirical investigation into the elements affecting the overall performance of SMEs in the retail quarter in Windhoek, Namibia, revealing that rent or lease a place for their commercial enterprise in Windhoek has prevented their performance. He discovered that it was once pricey to hire a working vicinity for business use in their present-day locations; therefore, most MSEs are unable to grow financially as the massive element of the income goes in the rental expenses. Access to land for business use in Windhoek used to be one additionally that hinders business performance.

The trade fair factor including trade show, trade exhibition, or expo is an exhibition organized so that companies in a specific industry can showcase and demonstrate their latest products and services, meet with industry partners and customers, study activities of rivals, and examine recent market trends and opportunities. In contrast to consumer 
fairs, only some trade fairs are open to the public, while others can only be attended by company representatives (members of the trade, e.g. professionals) and members of the press; therefore, trade shows are classified as either "public" or "trade only". There are presently many trade shows held every year, and several online directories have been established to help organizers, attendees, and marketers identify appropriate events (Morgan, 2014).

Overall performance is the act of performing or of doing something successfully; the use of knowledge as unique from in basic terms possessing it. However, performance seems to be conceptualized, operationalized, and measured in one-of-a-kind ways as a result making cross-comparison difficult. Business organizations should measure its overall performance with the use of set of financial and non-financial symptoms which provide statistics on degree of accomplishing their objective and result. Organizational overall performance entails the use of sources wisely to keep away from wastage. Given through the interaction between groups and environment, it follows that overall performance relates to how an employer reacts and is aware of the effect on positive surroundings change Global Entrepreneurship Monitor (GEM, 2004). Kamunge et al. (2014) used special performance warning signs like extend in sales, enterprise expansion, client retention, and increase in stock, waste reduction, and value discount in their study of elements affecting the performance of micro and small enterprise, while Mashimba and Kühl (2014) analyzed enterprise performance in phrases of business enterprise income and employer capital investment in machinery as a measure of performance. Moreover, Abera (2012) used profitability as a measure of performance in his evaluation of factors affecting the performance of micro and small companies in Arada and Lideta sub-cities of Addis Ababa. Based on assessment of related literature, performance of MSEs can be measured in terms of financial and non-financial symptoms, that is, increasing profit, growing sales/product or services, and capital developing for this study.

\section{Empirical reviews}

Vast number of studies performed on the overall performance of MSEs with a number of factors that determine enterprise surroundings of micro and small enterprises. Therefore, some of empirical research mentioned comply with:

Abdissa and Fitwi's (2016) study recognized that the exterior and internal factors affected overall performance of MSEs and their existence could improve the everyday operation of micro and small firms' performance. The study indicates variables such as political, legal, financial, marketing, working premises, infrastructural, probability seeking, persistence, commitment to the work, demand for affectivity and quality, goal setting, hazard taking, data seeking, and self-confidence are positively affecting the performance of MSEs (profit) in the study area. Similarly, for capital, variables such as political, legal, financial, marketing, working premises, technological, probability seeking, persistence, commitment to the work, demand for effectivity and quality, risk taking, statistics seeking, and self-confidence positively affected the overall performance of MSEs (capital) and significantly affect the performance of MSEs. In addition, for range of employees, variables such as political, financial, marketing, working premises, chance seeking, persistence, commitment to the work, demand for efficiency and quality, data seeking, and intention setting have positive impact on the performance of MSEs and 
substantially have an effect on overall performance of MSEs in phrases of quantity of employees. Hence improving these variables increases the overall performance of MSEs (profit, capital, and variety of employees).

Kebede and Simesh's (2015) studied the influence of internal and external enterprise environmental elements on the overall performance MSEs in East Gojam Zone, Ethiopia. Results from the study exhibit that infrastructure and monetary environment, technological surroundings, and factors associated with entrepreneurial commitment have a clear substantial relationship with performances of MSEs. Furthermore, based on the signal of the slope coefficients researchers located that infrastructure and finance had wonderful impacts on the overall performance of MSEs, while the rest has poor roles.

According to Fetene's (2017) study, results have shown that the eight hypothesized factors financial, management, marketing, entrepreneurial, technology, politico-legal, infrastructural, and working premises factors have been discovered substantially affecting the business performance of SMEs working in the study area and it was found that the monetary elements have been the most influencing predictor variable for SMEs' overall performance followed through infrastructure and politico-legal factors. Working premises were at the fourth role in phrases of its electricity in influencing commercial enterprise overall performance followed through administration and advertising and marketing factor.

Abera (2012) finds out the eight most important challenges which appear to affect overall performance of MSEs which include inadequate finance, lack of working premises, advertising and marketing problems, inadequate infrastructures, negative management practices, and technological, entrepreneurial, and politico-legal problems which include bureaucratic bottlenecks system. The findings similarly point out that there exists linear and superb massive ranging from tremendous to strong relationship which was located between independent variables and dependent variable

\section{Conceptual framework}

According to (Nabintu N. Factors affecting the performance of small and micro enterprises, Unpublished), conceptual framework is a diagrammatic presentation of the

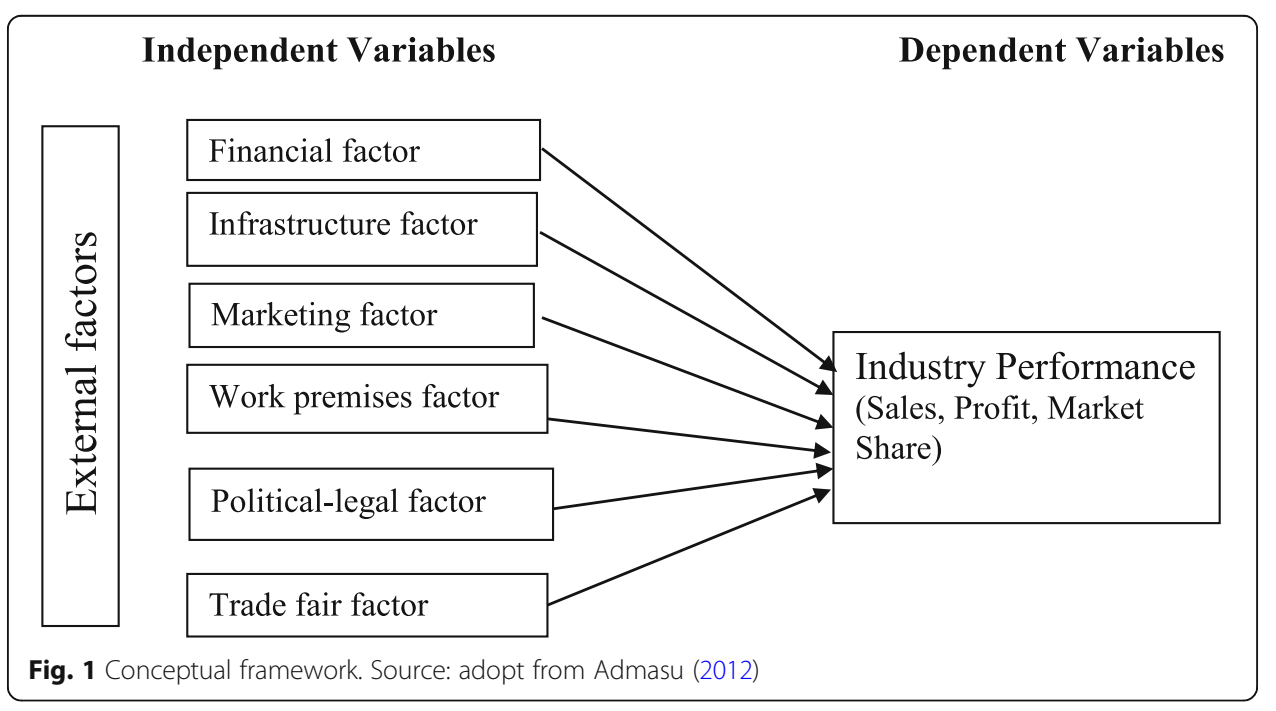


relationship between dependent and independent variables (Fig. 1). In this study, the dependent variable is performance of SMEs while independent variables are financial factors, marketing factors, infrastructure factors, legal factors, and trade fair factors.

\section{The current study}

The study aimed at analyzing the effect of external factors on industry performance in the study area. Based on the overall findings of the study, the general conclusions and recommendations are drawn. Thus, the study has six major hypotheses:

Hypothesis A1: Financial factor has a significant effect on industry performance in the study area.

Hypothesis A1: Marketing factor has a significant effect on industry performance.

Hypothesis A1: Infrastructural factors have a significant effect on industry performance.

Hypothesis A1: Work premise factors have a significant effect on industry performance in the study area.

Hypothesis A1: Political-legal factors have a significant effect on industry performance in the case area.

Hypothesis A1: Trade fair factors have a significant effect on industry performance in the case area.

\section{Methodology}

Methodologically, the study followed quantitative research approach and it used explanatory study type with cross-sectional survey design. To explain position of variables studied and effect of one variable to another variable, it is advisable to use this design. For the purpose of this study, both the primary and secondary sources data are utilized to achieve the objective of the study. Primary data was collected directly from the owners of the MSEs with standardized close-ended questionnaires used to collect data necessary to meet the objectives of the study. And also, secondary data was collected through the various sources like previously published materials as a literature review especially research papers, organization's reports, and Internet websites. The target population were considered as all MSEs' owners working in manufacturing, service, and trade industries in the study area. The total population of the study was 395 MSEs. Based on Taro Yamane (1967), sample size determination formula $\left(n=N /\left(1+N e^{\wedge} 2\right)\right)$, the researcher got a grand total sample size of 199, at $95 \%$ confidence level and 0.05 precision levels. The researcher applied stratified and simple random sampling techniques to collect the data. And also the collected data was analyzed through correlation and multiple linear regression analysis.

\section{Materials}

Measures of variables (external factors and industry performance)

The independent variables were measured using the total of 29-item questions including five political-legal factors, five work premise factors, five infrastructure factors, five marketing factors, five financial factors, and four trade fair factors. And also the dependent variable industry performance was measured using 5-item questions. Both the dependent and independent variables were measured with 5-point Likert scale response range (from 5 (strongly agree) to 1 (strongly disagree)). The variables used to 
measure the items on the instrument had been ordinal scale (strongly agree, to strongly disagree) because the nature of this study is quantitative.

\section{Results}

\section{Scale reliability}

When we see the reliability, it was statistically tested by using the most commonly used statistics Cronbach's alpha coefficient and all seven scales had a high level of reliability: financial factor (alpha $=.832$ ), marketing factor (alpha $=.824$ ), infrastructural factors (alpha $=.781)$, work premise factors (alpha $=.696)$, political-legal factors (alpha $=.729$ ), trade fair factors (alpha $=.626$ ), and performance (alpha $=.706$ ).

\section{Descriptive analysis}

In this study, descriptive analysis was used to observe the level of agreement to the find out about variables; mean and standard deviation were used to measure the responses dispersion degree from arithmetic mean. Therefore, the end result of this study was analyzed using this standard to decide the relative importance for interpretation whether it fails in 11.80 very low, $1.80-2.60$ low, $2.60-3.40$ medium, $3.40-4.20$ high, and $4.20-5.00$ very high.

Table 1 result indicates that the descriptive statistics result of marketing factor, financial factors, infrastructure factors, work premises factors, trade fair factors, and performance measurement factors has grand mean of 2.7296, 2.7402, 2.8111, 2.9266, 2.6417, and 2.8854 at a standard deviation of .78101, .85185, .77699, .73226, .61338, and .73645 respectively. This clearly shows that the majority of the respondent response level of agreement falls into medium range. But political-legal factors mean value was 2.2050 with standard deviation of .48635 . This indicates that the majority of the respondent level of agreement is closer to low range. Furthermore, the standard deviation result indicates the extent to which the respondents' opinions about the statements on external factors and performance varied.

\section{Correlational analyses}

For the purpose of this study, the researcher used Pearson product moment correlation analysis to find out the relationship of independent variables (marketing factor, financial factors, infrastructure factors, work premises factors, political factors, and trade fair factors) with the dependent variable industry performance. According to Cohen (1992), an interpretation of the range of the coefficient of correlation has been described into

Table 1 Descriptive statistics

\begin{tabular}{llll}
\hline & Mean & Std. deviation & N \\
\hline Total marketing factor & 2.7296 & .78101 & 199 \\
Total financial factors & 2.7402 & .85185 & 199 \\
Total infrastructure & 2.8111 & .77699 & 199 \\
Total political-legal factors & 2.2050 & .48635 & 199 \\
Total work premise factors & 2.9266 & .73226 & 199 \\
Total trade fair factors & 2.6417 & .61338 & 199 \\
Total performance measurement factors & 2.8854 & .73645 & 199 \\
\hline Source: own survey, 2019 & & &
\end{tabular}


the following: -0.3 to +0.3 weak; -0.5 to -0.3 or 0.3 to 0.5 moderate; -0.5 to -0.9 or 0.5 to 0.9 strong; and -0.9 to -1 or 0.9 to 1 very strong.

Based on Table 2 Pearson product moment correlation analysis result, there was a strong positively significant relationship between the dependent variables marketing factor, financial factors, infrastructure factors, and work premises factors with the dependent variable industry performance at correlation coefficient of $0.720,0.539,70.731$, and 0.673 respectively. And also there was a weak positively significant relationship between independent variables (political factors and trade fair factors) with industry performance at correlation coefficient of 0.187 and 0.221 respectively. Generally, the study finds out there is existence of a positively significant relationship between overall external factors and industry performance at significance level of $r<0.01$ in the case area.

The study result showed that there is not a problem of multicollinearity, normality, and linearity in the study variables.

\section{Regression analysis}

Multiple regression analysis result portrays that $R$ square is .674 and adjusted $R$ square is .664 (Table 3). This implied that $67.4 \%$ variation in industry performance is explained by external factor in the study area. In addition, the significance value of $F$ statistics indicates a value .000 and it was less than $p<0.05$, so that it means the model was significant enough.

Based on Table 4 result, infrastructural factor was the most contributing factor for the dependent variable industry performance in the study area. Since the beta value is 0.319 with significance level 0.000 and marketing factor's beta value is $B=0.296$ at sig. 0.000 , this implies that that marketing factor has a positive significant effect on industry performance and the second most contributing factor for the dependent variable. In addition, independent variables financial factors, work premise factors, and trade fair factors have a positive significant effect on industry performance at beta value of $0.124,0.199$, and 0.123 at sig. level of 0.014, 0.001, and 0.004 respectively. As a result, the regression coefficient clarifies the average amount of change in industry performance was affected by a unit of change in external factors by the stated beta value. Contrarily, political-legal factor has no significant effect on industry performance at sig. 0.996 (Table 5).

\section{Discussions}

The mean score of independent variables showed that most employees' feeling result was approaching to moderately agreed on measures of marketing factor, financial factors, infrastructure factors, work premises factors, trade fair factors, and performance measurement factors. However, political-legal factors mean value indicates that the majority of the respondents' level of agreement is closer to low range. The correlation result indicated that all the external factors have a significantly positive relationship with industry performance. Based on the study result, $67.4 \%$ of variation in industry performance is explained by industry performance in MSEs and the other $22.6 \%$ is explained by other factors not included in this study. And also, the model was significant at $p=000$. The effect analysis result showed that independent variables marketing factor, financial factors, infrastructure factors, work premises factors, and trade fair factors have a positive significant effect on the dependent variable industry performance at beta value of $0.124,0.199$, and 0.123 at sig. level of $0.014,0.001$, and 0.004 respectively. 


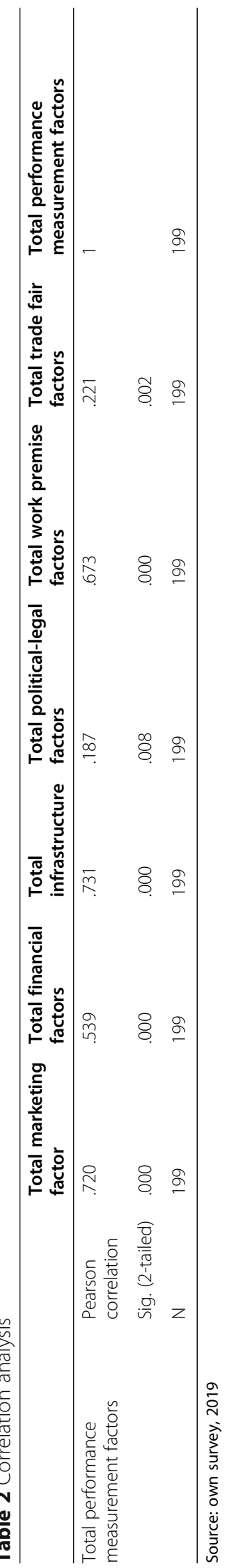


Table 3 Regression analysis

\begin{tabular}{|c|c|c|c|c|c|c|c|}
\hline \multirow[t]{2}{*}{ Model } & \multirow[t]{2}{*}{$R$} & \multirow{2}{*}{$\begin{array}{l}R \\
\text { Square }\end{array}$} & \multirow{2}{*}{$\begin{array}{l}\text { Adjusted } \\
R \text { Square }\end{array}$} & \multirow{2}{*}{$\begin{array}{l}\text { Std. } \\
\text { error of } \\
\text { the } \\
\text { estimate }\end{array}$} & \multicolumn{3}{|l|}{ Change statistics } \\
\hline & & & & & $R$ square change & Sig. $F$ change & Durbin-Watson \\
\hline 1 & .821 & .674 & .664 & .42695 & .674 & .000 & 1.860 \\
\hline
\end{tabular}

But political factors have no significant effect on industry performance in study area MSEs at sig. 0.996. In conclusion, the regression coefficient elucidates that the average amount of change in industry performance was affected by a unit of change in external factors by the stated beta value.

Finally, this study objective is meted up well by originated findings as previously supposed.

\section{Recommendations}

The empirical result confirmed that there is a significant relationship with eternal variables and industry performance in the study area and also infrastructural factor and marketing factors are the key contributors to MSEs' performance. Accordingly, the government should seek a great attention and solve these infrastructural and marketing problems to increase the performance of MSEs as well as to support the country's economy as expected. Because creating a favorable marketing/work environment and sufficient infrastructure will motivate MSEs and increase their effectiveness in their business activity.

In the study area there is a big gap of source of finance and getting loan from different financial institutions is low with higher interest rate, Consequently, the study recommends that micro and small enterprises development office is better to collaborate/ integrated with credit and saving associations to give admission to affordable and principal source of finance for MSEs to reduce their requirement producers and increase their performance; then, they will play their role in poverty reduction in the country. In addition, the owners/managers of MSEs might also develop adequate and appropriate marketing strategy and participate in different trade fair activities/programs to display their products/services to meet industry buddies and loyal customers.

Generally, the study recommends that the government/ micro and small enterprises development offices should maintain different supportive business trainings, decrease

Table 4 Coefficients (dependent variable: total performance factors)

\begin{tabular}{|c|c|c|c|c|c|c|}
\hline \multirow{2}{*}{\multicolumn{2}{|c|}{ Model }} & \multicolumn{2}{|c|}{ Unstandardized coefficients } & \multirow{2}{*}{$\begin{array}{l}\text { Standardized coefficients } \\
\text { Beta }\end{array}$} & \multirow[t]{2}{*}{$t$} & \multirow[t]{2}{*}{ Sig. } \\
\hline & & $B$ & Std. Error & & & \\
\hline \multirow[t]{7}{*}{1} & (Constant) & .004 & .203 & & .019 & .985 \\
\hline & Total political-legal factors & .000 & .066 & .000 & -.005 & .996 \\
\hline & Total marketing factor & .279 & .059 & .296 & 4.707 & .000 \\
\hline & Total financial factors & .108 & .043 & .124 & 2.481 & .014 \\
\hline & Total infrastructure factors & .302 & .060 & .319 & 5.024 & .000 \\
\hline & Total work premises factors & .200 & .060 & .199 & 3.308 & .001 \\
\hline & Total trade fair factors & .148 & .051 & .123 & 2.896 & .004 \\
\hline
\end{tabular}

Source: own survey, 2019 
Table 5 Hypothesis testing

\begin{tabular}{|c|c|c|}
\hline No. & Hypothesis & Decision rule \\
\hline 1 & $\begin{array}{l}\text { Hypothesis A1: Financial factor has a significant effect on industry } \\
\text { performance in the study area }\end{array}$ & $\begin{array}{l}\text { Accept alternative hypothesis and } \\
\text { reject null hypothesis }\end{array}$ \\
\hline 2 & $\begin{array}{l}\text { Hypothesis A1: Marketing factor has a significant effect on } \\
\text { industry performance }\end{array}$ & $\begin{array}{l}\text { Accept alternative hypothesis and } \\
\text { reject null hypothesis }\end{array}$ \\
\hline 3 & $\begin{array}{l}\text { Hypothesis A1: Infrastructural factors have a significant effect on } \\
\text { industry performance }\end{array}$ & $\begin{array}{l}\text { Accept alternative hypothesis and } \\
\text { reject null hypothesis }\end{array}$ \\
\hline 4 & $\begin{array}{l}\text { Hypothesis A1: Work premise factors has a significant effect on } \\
\text { industry performance in the study area }\end{array}$ & $\begin{array}{l}\text { Accept alternative hypothesis and } \\
\text { reject null hypothesis }\end{array}$ \\
\hline 5 & $\begin{array}{l}\text { Hypothesis A1: Political legal factors have a significant effect on } \\
\text { industry performance in the case area }\end{array}$ & $\begin{array}{l}\text { Reject alternative hypothesis and } \\
\text { Accept null hypothesis }\end{array}$ \\
\hline 6 & $\begin{array}{l}\text { Hypothesis A1: Trade fair factors has a significant effect on } \\
\text { industry performance in the case area }\end{array}$ & $\begin{array}{l}\text { Accept alternative hypothesis and } \\
\text { reject null hypothesis }\end{array}$ \\
\hline
\end{tabular}

Source: own survey, 2019

infrastructural problems, facilitate credit services, and create attractive marketing environment to entice or create productive MSEs. In addition, the MSEs' owners should design adoptive business plans and programs with the external as well as internal environment to increase their performance.

\section{Conclusions}

In the present paper, the researcher attempts to evaluate the effect of external factors on industry performance in the study area MSEs. In the study, various parameters are used to evaluate the performance of MSEs and external factors. The study has six independent variables and one dependent variable. To achieve the research objectives, the statistical relationship of each independent variable with the dependent variable was well examined and presented in the study in line with the study questions. After evaluating all the parameters exclusively, the researcher found that all the independent variables excluding political-legal factors have a significant effect on industry performance in the study area and infrastructural factor was the most contributing factor for performance. Hence, in the end, we can conclude that the external factor has a significant effect on industry performance.

\section{Suggestion for future study}

The researcher conducted more of quantitative study; deep qualitative study could also be done to validate the results of this study. From the findings of the study, it is concluded that the model which was included in external factors explained only $67.4 \%$ of the variance of industry performance and the rest $22.6 \%$ may be due to the other variables which were not included in this study and left for further study.

\section{Abbreviations}

EAO: Entrepreneurial Attitude Orientation; EC: Entrepreneurial culture

\section{Acknowledgements}

The author would like to thank my academic staff member, reviewers, and other contributors for the improvement of this article. 


\section{Funding}

No funding information, but am eligible for waiver opportunities on Springer journals.

\section{Availability of data and materials}

All the metadata used under the research process is available on hand: for instance, look for the spss data output here.

\section{Competing interests}

The author declares that there are no competing interests.

Received: 29 October 2020 Accepted: 19 January 2021

Published online: 01 March 2021

\section{References}

Abdissa, G., \& Fitwi, T. (2016). Factors affecting the performance of micro and small enterprises in South West Ethiopia: The case of Bench Maji, Sheka, and Kefa zones. Global Journal of Management and Business Research, 16(10), https:// journalofbusiness.org/index.php/GJMBR/article/view/2169.

Abera, A. (2012). Factors affecting the performance of micro and small enterprises in Arada and Lideta Sub-Cities. Addis Ababa: Addis Ababa University. http://localhost:80/xmlui/handle/123456789/13199.

Akinruwa, T. E., Awolusi, O. D., \& Ibojo, B. O. (2013). Determinants of small and medium enterprises (SMEs) performance in Ekiti State, Nigeria: A business survey approach. European Journal of Humanities and Social Sciences, 27(1), 1397-1413.

Amwele, H. N. (2013). An empirical investigation into the factors affecting the performance of SMEs in the retail sector in Windhoek, Namibia (Master thesis, Harold Pupkewitz Graduate School of Business at the Polytechnic of Namibia).

Admasu, A. (2012). Factors Affecting the Performance of Micro and Small Enterprises in Arada and Lideta Sub-Cities, Addis Ababa (Doctoral Dissertation, Addis Ababa University). Retrieved from http://etd.aau.edu.et/bitstream/handle/123456789/13199/.

Belete, W. (2015). Human capital barriers to technological absorption and innovation by Ethiopia's micro and small enterprises (MSEs): thematic report. The African Journal of Information and Communication, 2015(16), 73-77.

Cohen, J. (1992). Statistical Power Analysis. Current Directions in Psychological Science, 1(3), 98-101. https://doi.org/10.1111/ 1467-8721.ep10768783.

Davidsson, P. (1989). A study of growth willingness in small firms. Journal of Business Venturing, 4(3), 211-226.

EDRI (Ethiopian Development Research Institute) (2014). Identifying Key Success Factors and Constraints in Ethiopia's MSE Development: An Exploratory Research (Research Report 18). Addis Ababa, Ethiopia: Ethiopian Development Research Institute.

Fetene, A. (2017). Factors affecting the business performance of the small and medium-sized enterprises (SMES) in Addis Ababa, Ethiopia: (In Case of Nifas Silk-Lafeto Sub-City) (Master thesis, St. Mary's University). Retrieved from http://repository.smuc. edu.et/bitstream/123456789/3292/1/MBA-G\%20Thesis\%20\%28Atalel-Jan-26-\%202017\%29.pdf.

Government of Federal Democratic Republic of Ethiopia (GFDRE) (2011). MSEs development, support scheme, and implementation strategies. Addis Ababa, Ethiopia.

Global Entrepreneurship Monitor (GEM) (2004). Women and entrepreneurship. Center for women's leadership. Banson College. MA, USA.

Kamunge, M. S., Njeru, A., \& Tirimba, O. I. (2014). Factors affecting the performance of small and micro enterprises in Limuru Town Market of Kiambu County. Kenya. International Journal of Scientific and Research Publications, 4(12), 1-20.

Kebede, M., \& Simesh, G. (2015). The impact of environmental factors on the performance of micro \& small-scale enterprises in East Gojjam zone, Ethopia. International Journal of Science and Research, 6(3), 1619-1629.

Lencho, D. M. (2019). Assessment of factors affecting performance of micro and small scale enterprises. Reviewed Journal International of Business Management [ISSN 2663-127X], 1(1), 20-41.

Mashimba, S. H., \& Kühl, R. (2014). Performance of micro and small-scale enterprises (MSEs) in Tanzania: growth hazards of fruit and vegetables processing vendors. Journal of Applied Economics \& Business Research, 4(2). https://www.scribd.com/ document/340394186/3-mashimba-kuhl.

Mengstie, B. (2016). Impact of business development services on performance of micro and small enterprises in East Amhara Region of Ethiopia. European Journal of Business and Management, 8(4), 179-187.

Mezgebe, W. (2012). Problems of micro and small enterprises in Addis Ababa: The Case of Kirkos, Kolfe, and Yeka Sub Cities. Addis Ababa: Addis Ababa University. http://etd.aau.edu.et/handle/123456789/13826.

Morgan, B. (2014, September 15). Trade Show Displays A Buyer's Guide. Business News Daily.

Mulugeta, E. (2008). Underlying causes of micro and small business failures in Addis Ketema Sub City: a case study. Addis Ababa: Addis Ababa University. http://localhost/xmlui/handle/123456789/3213.

Namusonge, G. (2010). Determinants of growth oriented small and medium enterprises: A survey of Nairobi Province. Düsseldorf: VDM Verlag Dr. Müller.

UNDP (2004). Human Development Report. Overcoming barriers: Human mobility and development. New York: UNDP.

World Bank Group (WBG) (2011). Ethiopia country profile, Enterprise survey. Retrieved from https://openknowledge. worldbank.org/handle/10986/20825.

Yamane, T. (1967). Sample size calculation. New York: Harper Press.

\section{Publisher's Note}

Springer Nature remains neutral with regard to jurisdictional claims in published maps and institutional affiliations. 